\title{
Australian bat lyssavirus infection in two horses
}

\author{
Mustaghfira Wafa Shinwari ${ }^{\mathrm{a}}$, Edward J. Annand ${ }^{\mathrm{b}}$, Luke Driver ${ }^{\mathrm{a}}$, \\ David Warrilow ${ }^{\mathrm{c}}$, Bruce Harrower ${ }^{\mathrm{c}}$, Richard J.N. Allcock ${ }^{\mathrm{d}, \mathrm{e}}$, Dennis Pukallus ${ }^{\mathrm{c}}$, \\ Jennifer Harper ${ }^{\mathrm{f}}$, John Bingham ${ }^{\mathrm{f}}$, Nina Kung ${ }^{\mathrm{g}}$, Ibrahim S. Diallo ${ }^{\mathrm{a}, *}$ \\ a Biosecurity Sciences Laboratory, Department of Agriculture, Fisheries and Forestry, 39 Kessels Road, Coopers Plains, QLD 4108, Australia \\ ${ }^{\mathrm{b}}$ Randwick Equine Centre, Sydney, NSW 2031, Australia \\ ${ }^{\mathrm{c}}$ Public Health Virology Laboratory, Queensland Health Forensic and Scientific Services, P.O. Box 594, Archerfield, QLD 4108, Australia \\ ${ }^{\mathrm{d}}$ LotteryWest State Biomedical Facility - Genomics, School of Pathology and Laboratory Medicine, University of Western Australia, Perth, \\ Western Australia, Australia \\ e Department of Diagnostic Genomics, Pathwest Laboratory Medicine WA, PP Block, Sir Charles Gairdner Hospital, Perth, Western Australia, \\ Australia \\ ${ }^{\mathrm{f}}$ CSIRO, Australian Animal Health Laboratory, 5 Portarlington Road, Geelong, VIC 3220, Australia \\ ${ }^{\mathrm{g}}$ Department of Agriculture, Fisheries and Forestry, Ann Street, Brisbane, QLD 4000, Australia
}

\section{A R T I C L E I N F O}

\section{Article history:}

Received 10 April 2014

Received in revised form 11 July 2014

Accepted 27 July 2014

\section{Keywords:}

Australian bat lyssavirus

Equine non-suppurative meningoencepha-

lomyelitis

Negri bodies

Yellow-bellied sheathtail bat

\begin{abstract}
A B S T R A C T
In May 2013, the first cases of Australian bat lyssavirus infections in domestic animals were identified in Australia. Two horses (filly-H1 and gelding- $\mathrm{H} 2$ ) were infected with the Yellow-bellied sheathtail bat (YBST) variant of Australian bat lyssavirus (ABLV). The horses presented with neurological signs, pyrexia and progressing ataxia. Intra-cytoplasmic inclusion bodies (Negri bodies) were detected in some Purkinje neurons in haematoxylin and eosin (H\&E) stained sections from the brain of one of the two infected horses (H2) by histological examination. A morphological diagnosis of sub-acute moderate nonsuppurative, predominantly angiocentric, meningo-encephalomyelitis of viral aetiology was made. The presumptive diagnosis of ABLV infection was confirmed by the positive testing of the affected brain tissue from $(\mathrm{H} 2)$ in a range of laboratory tests including fluorescent antibody test (FAT) and real-time PCR targeting the nucleocapsid (N) gene. Retrospective testing of the oral swab from (H1) in the real-time PCR also returned a positive result. The FAT and immunohistochemistry (IHC) revealed an abundance of ABLV antigen throughout the examined brain sections. ABLV was isolated from the brain (H2) and oral swab/saliva (H1) in the neuroblastoma cell line (MNA). Alignment of the genome sequence revealed a $97.7 \%$ identity with the YBST ABLV strain.
\end{abstract}

Crown Copyright $\odot 2014$ Published by Elsevier B.V. All rights reserved.

\section{Introduction}

Australian bat lyssavirus (ABLV) belongs to the genus Lyssavirus of the family Rhabdoviridae within the order Mononegavirales (ICTV, http://www.ictvonline.org/virus-

\footnotetext{
* Corresponding author. Tel.: +61 73276 6051; fax: +61 732166610

E-mail address: ibrahim.diallo@daff.qld.gov.au (I.S. Diallo).
}

Taxonomy.asp). The genus is represented by rabies virus (RABV, genotype 1) and comprises Lagos bat virus (LBV, genotype 2), Mokola virus (MOKV, genotype 3), Duvenhage bat virus (DUVV, genotype 4), European bat lyssavirus 1 and 2 (EBLV-1 and 2, genotypes 5 and 6, respectively), Australian bat lyssavirus (ABLV, genotype 7), Irkut bat virus (IRKV, genotype 8), Aravan bat virus (genotype 9), Khujand bat virus (KHUV, genotype 10), West Caucasian bat virus (WCBV, genotype 11) and Shimoni bat virus 
(SHIBV, yet to be classified). Based on sequence analysis, ABLV is related to other bat lyssaviruses but it is most closely related to classical rabies virus (Gould et al., 1998). Hence, the cross-protection against ABLV infection provided by currently used rabies vaccines (Fooks, 2004). ABLV causes similar neurological symptoms to rabies in humans (Allworth et al., 1996; Hanna et al., 2000; Samaratunga et al., 1998). ABLV was first described in a black flying fox (Pteropus alecto) in 1996 by Fraser et al. (1996); however, retrospective testing of archival brain tissues indicated that there was an earlier case in 1995. This variant was also detected in the grey-headed flying fox (Pteropus poliocephalus), the spectacled flying fox (Pteropus conspicillatus) and the little red flying fox (Pteropus scapulatus). Another variant of ABLV was later isolated from a species of insectivorous microbat, the Yellow-bellied sheath tail bat (YBST) (Saccolaimus flaviventris) (Gould et al., 2002; Hooper et al., 1997). Therefore, there are two distinct variants of ABLV affecting frugivorous and insectivorous bats, respectively.

Spill-over of bat lyssavirus infection have been previously reported and bat lyssaviruses are known to infect humans, domestic animals and wildlife (Fooks et al., 2003; Müller et al., 2004; Ronsholt, 2002). In 2009, Dacheux et al. (2009) suspected bat-to-cat transmissions of EBLV on two occasions, when EBLV-1 was recovered from 2 domestic cats in France. Similarly, (Müller et al., 2004 ) reported a lyssavirus infection in a stone marten in Germany. Furthermore, Brookes et al. (2007) reproduced the disease experimentally in sheep, and Cliquet et al. (2009) compared the susceptibility of foxes to EBLV type 1 and 2 using intracranial and peripheral (intramuscular) inoculation methods and demonstrated a low spill-over chance of EBLV from bat to fox with EBLV-1 having a greater probability to do so than EBLV-2. In a series of experiments, Vos et al. (2004a,b) infected ferrets and foxes with EBLV-1, however they showed that these species were unlikely to transmit the virus to another host. In the United States of America, it has been shown that spill-over events have occurred and have resulted in the permanent adaptation of bat lyssavirus variants in raccoons, skunks, foxes, coyotes, mongooses, groundhogs and bobcats (Krebs et al., 2000). Similar events have been reported in Africa, particularly in Southern Africa, with adaptation of bat lyssavirus variants in mongooses, jackals and bat-eared foxes (Bengis et al., 2004). In South America, there have been reports of transmission of bat lyssavirus from wildlife, especially vampire bats (Favoretto et al., 2013).

According to the recommendations of the World Health Organization (WHO) and the World Organization for Animal Health (OIE), the fluorescent antibody test (FAT) is the method of choice for the identification of lyssavirus in the brain stem (thalamus, pons and medulla). Although FAT is the gold standard assay for the identification of lyssavirus in tissues, in recent years advances in molecular diagnostics have seen wide use of conventional and realtime RT-PCR for the diagnosis of lyssavirus infections (Banyard et al., 2009; Black et al., 2002; Echevarría et al., 2001; Foord et al., 2006; Smith et al., 2002; VázquezMorón et al., 2006; Wakeley et al., 2005).
Until recently, the only cases of lyssavirus infection recorded in Australia were in bats and humans. However, in May 2013 two horses were diagnosed with ABLV and are the first confirmed Australian field infections. We describe these 2 cases and discuss the relevance of these findings to the management of ABLV infections in domestic animals in Australia.

\section{Materials and methods}

\subsection{Clinical presentation}

\subsubsection{Horse $1(\mathrm{H} 1)$}

On May 5, 2013, a female yearling presented with pyrexia, subtle neurological signs and progressive ataxia. The attending equine practitioner submitted blood (EDTA), nasal, rectal and oral swabs to the Biosecurity Sciences Laboratory (BSL) for Hendra virus ( $\mathrm{HeV}$ ) testing. However, the horse deteriorated and it was euthanized, and no further samples were taken. Samples were tested the same day and were negative. As a differential diagnosis, the submitting veterinarian requested tests for flavivirus infection which were negative.

\subsubsection{Horse 2 (H2)}

Within four days of $\mathrm{H} 1$ becoming symptomatic, a male yearling from the same paddock presented with similar neurological signs. Samples were submitted for $\mathrm{HeV}$, equine herpesvirus type 1 and flavivirus testing; all samples were negative. $\mathrm{H} 2$ deteriorated over the following 3 days and was euthanized. On advice of the duty pathologist, the veterinarian performed a necropsy and submitted samples preserved in 10\% neutral buffered formalin and unpreserved samples from the central nervous system to BSL for testing. The preserved samples included small pieces of cerebral cortex, cerebellum, brain stem and spinal cord. The rest of the brain and cerebrospinal fluid were unpreserved. The unpreserved brain was stored at $-20^{\circ} \mathrm{C}$ after being sub-sampled for further testing soon after its delivery to the laboratory; therefore, further histological examination was not possible.

\subsection{Histopathology}

Central nervous system specimens including small portions of cerebral cortex, cerebellum, brain stem and cervical spinal cord from horse 2 were fixed in $10 \%$ neutral buffered formalin, and embedded in paraffin. Sections were cut at $4 \mu \mathrm{m}$ thickness using a microtome (Microm HM325, Thermo), stained with haematoxylin and eosin (H\&E) and examined.

\subsection{Immunohistochemistry (IHC)}

Additional sections for IHC were cut onto positively charged slides and placed in a $40{ }^{\circ} \mathrm{C}$ incubator to dry overnight. Following $10 \mathrm{~min}$ incubation in a $60^{\circ} \mathrm{C}$ oven, the slides were dewaxed and brought to water.

Antigen retrieval was induced through heat treatment by placing the sections in EnVision Flex Target Retrieval Solution, High pH (Dako, Denmark) for $30 \mathrm{~min}$ at $97^{\circ} \mathrm{C}$ 
using the Dako PT Link. Following treatment and a 5 min wash in EnVision Flex Wash Buffer, the slides were placed onto the Dako Autostainer where endogenous peroxidases were quenched with $3 \%$ hydrogen peroxide for $10 \mathrm{~min}$. Slides were then rinsed with buffer and the primary antibody was applied for $60 \mathrm{~min}$. Sections were then rinsed with buffer and a secondary antibody, EnVision Flex/HRP (Dako, Denmark), was applied for $20 \mathrm{~min}$, followed by a further rinse of buffer and application of AEC + High Sensitivity Substrate Chromogen (Dako, Denmark) for $10 \mathrm{~min}$. Following a distilled water rinse, sections were removed from the Autostainer, counterstained with LillieMayer's haematoxylin and mounted using Dako Faramount Aqueous Mounting Medium (Dako, Denmark). Five primary antibodies were used, each on separate slides: a monoclonal antibody 5DF12 (supplied by Alex Wandeler, formerly of the Centre of Expertise for Rabies, Canadian Food Inspection Agency, Ottawa), and four rabbit antisera raised against the nucleoprotein of rabies virus (CSIRO Australian Animal Health Laboratory, Geelong, Australia).

\subsection{Cell culture and virus isolation}

The mouse neuroblastoma cell line, MNA, was maintained in growth medium (Opti-MEM with 3\% FCS, $100 \mathrm{U} /$ $\mathrm{mL}$ of penicillin, $100 \mu \mathrm{g} / \mathrm{mL}$ of streptomycin and $0.25 \mu \mathrm{g} /$ $\mathrm{mL}$ of Fungizone ${ }^{\mathbb{R}}$ ) at $37{ }^{\circ} \mathrm{C}$ under $5 \% \mathrm{CO}_{2}$. To obtain a viral isolate, a suspension of infected horse brain was ground then filtered $(0.22 \mu \mathrm{m})$ and used to infect a monolayer of MNA cells. After initial infection, four weekly serial passages were performed, and successful infection was confirmed by immuno-fluorescence antibody test on fixed cells.

\subsection{Direct immunofluorescent antibody assay (FAT)}

FAT uses a monoclonal antibody conjugated with fluorescein isothiocyanate (FITC, Fujirebio Diagnostics, Sweden). Brain tissue was cross-sectioned and impression smears were done on a microscope slide. The slides were fixed in acetone for $1 \mathrm{~h}$ at room temperature and allowed to air dry. Two drops of FITC-conjugated monoclonal antibody were added to the smear and incubated in a humid chamber at room temperature for $30 \mathrm{~min}$. Unbound antibody was washed off with phosphate buffered saline (PBS) and the slides were mounted with cover slips using glycerol mounting medium (90\% glycerol in PBS). Slides were examined using a fluorescent microscope (Leitz Laborlux II). Negative and positive controls were included in the assay.

\subsection{Multiplex real-time $P C R$}

RNA was extracted from brain and oral swabs using the EZ-1 robot (Qiagen, Australia). RNA was tested using a multiplex real-time PCR which combines two fluorogenic assays targeting the nucleocapsid gene of both variants of ABLV as described by Smith et al. (2002). Five microlitres of RNA template was added to $20 \mu$ l of SuperScript ${ }^{\mathrm{TM}}$ Platinum III One-step RT PCR mastermix. The PCR was run using fast cycling parameters $\left[50^{\circ} \mathrm{C}\right.$ for $5 \mathrm{~min} ; 95^{\circ} \mathrm{C}$ for
2 min $]_{1}\left[95{ }^{\circ} \mathrm{C} \text { for } 3 \mathrm{~s} ; 60{ }^{\circ} \mathrm{C} \text { for } 30 \mathrm{~s}\right]_{40}$ Fluorescence signal was acquired on the FAM channel (for frugivorous ABLV variant) and VIC (for YBST ABLV variant) channel. For quality assurance purposes, negative and positive controls were included in the run.

\subsection{Sequence-independent amplification}

Cell debris was removed from the viral tissue culture supernatant by centrifugation (3000 rpm; $10 \mathrm{~min}$; room temperature) followed by filtration $(0.22 \mu \mathrm{m})$. Contaminating nucleic acids were removed by enzymatic digestion with RQ1 DNase $(1 \mathrm{U} / \mathrm{ml})$ and RNase ONE $(2 \mathrm{U} / \mathrm{ml})$ at $37^{\circ} \mathrm{C}$ for $30 \mathrm{~min}$. Ultra-centrifugation was used to sediment virus particles $\left(100,000 \times g\right.$; SwTi55 rotor; $\left.2 \mathrm{~h} ; 4^{\circ} \mathrm{C}\right)$ which were resuspended in sterile PBS on ice overnight. A QIAamp Viral RNA extraction kit (Qiagen) was used for nucleic acid extraction as per manufacturer's recommendations; however, carrier RNA was omitted from the AVL buffer. Reverse transcription was performed using the extracted RNA ( $5 \mu \mathrm{L})$ as template and random hexamers attached to an arbitrary sequence (C-6N 5'-GAGAAACCCACCACCAGANNNNNN-3'). Second strand DNA synthesis was performed using the SuperScript ${ }^{\mathrm{TM}}$ III One-Step RTPCR System with Platinum ${ }^{\circledR}$ Taq High Fidelity mix (Life Technologies) with the following cycling conditions $\left[25^{\circ} \mathrm{C}\right.$ for $5 \mathrm{~min}$; $37^{\circ} \mathrm{C}$ for $30 \mathrm{~min}$; $95^{\circ} \mathrm{C}$ for $\left.2 \mathrm{~min}\right]_{1}\left[95^{\circ} \mathrm{C}, 30 \mathrm{~s}\right.$; $\left.25^{\circ} \mathrm{C}, 30 \mathrm{~s} ; 72^{\circ} \mathrm{C}, 2 \mathrm{~min}\right]_{5}$. The cDNA $(2 \mu \mathrm{L})$ was used as a template for amplification in a mix containing a primer with the arbitrary sequence shown above (Primer $C 5^{\prime}$ GAGAAACCCACCACCAGA-3') and AmpliTaq Gold thermostable DNA polymerase. The cycling parameters were as follows: $\left[95^{\circ} \mathrm{C}, 12 \mathrm{~min}\right]_{1}\left[95^{\circ} \mathrm{C}, 30 \mathrm{~s} ; 59^{\circ} \mathrm{C}, 30 \mathrm{~s} ; 72^{\circ} \mathrm{C}\right.$, $2 \mathrm{~min}]_{50}\left[72^{\circ} \mathrm{C}, 7 \mathrm{~min}\right]_{1}\left[15^{\circ} \mathrm{C}\right]_{\text {hold. }}$

\subsection{Library preparation}

DNA samples were sheared to approximately 230-250 bp fragments using an S2 sonicator (Covaris Inc., MA, USA). Sequencing libraries were prepared using an NEBNext Ultra library kit (New England Biosciences) with local modifications and quantified using a High Sensitivity DNA chip on a Bioanalyzer 2100 (Agilent Technologies, CA, USA).

\subsection{Template preparation and sequencing}

Two barcoded samples were pooled in equimolar ratios to a total concentration of $12 \mathrm{pM}$ in low TE buffer $(10 \mathrm{mM}$ Tris- $\mathrm{HCl}+0.1 \mathrm{mM}$ EDTA). Template preparation and enrichment was performed using an Ion OneTouch2 Template 200 Kit (Life Technologies, NY, USA) on a OneTouch 2 and OneTouch ES (Life Technologies, NY, USA). Sequencing was performed using an Ion PGM 200 Sequencing Kit on a "316" sequencing chips for a total of 500 nucleotide flows, yielding average read lengths of 220-230bp. Primary analysis (i.e. base-calling and barcode de-convolution) was performed using Torrent Suite 3.6.2. Initially, reads were trimmed of adaptor sequences and filtered to remove polyclonal and low quality reads. They were then trimmed to remove poor quality bases at the $3^{\prime}$ end of long reads. 
A FASTQ file containing the output from PGM sequencing was imported into Geneious Pro software v5.6 (Kearse et al., 2012). The reads were then re-trimmed to remove 30 nucleotides from the $5^{\prime}$ and $3^{\prime}$ ends of each read. A virus consensus sequence was assembled from the trimmed data using Geneious Pro software v5.6 and using the ABLV YBST strain (NCBI accession number NC_003243.1) as a reference sequence, with the assembly sensitivity set at the highest level.

\subsection{Bioinformatics}

For nucleotide sequence identity scores, the Geneious Alignment feature was used (cost matrix 65\% similarity; gap open penalty, 12; gap extension penalty, 3). Multiple nucleotide sequence alignment was performed using the MAFFT plugin (scoring matrix 200PAM/k=2; gap open penalty, 1.53; offset value, 0.123). A mid-point rooted phylogenetic tree was generated with the multiple alignment output by the neighbour joining method of MEGA5 (Tamura et al., 2011) using the estimated gamma parameter (Jukes-Cantor model and complete gap deletion) with 1000 bootstrap replicates.

\section{Results}

\subsection{Histopathological findings}

Tissues were well preserved but some distortion, probably due to the sampling process, was evident in all of the examined sections. The histopathological findings consistent with a subacute non-suppurative meningoencephalomyelitis of viral aetiology (Fig. 1A) were present in all of the examined sections. The angiocentric cellular reaction mainly consisted of mononuclear cells including lymphocytes, macrophages, and reactive endothelial and glial cells. In addition, variable numbers of neutrophils were also present in some of the vasocentric foci. The perivascular cuffing and focal non-suppurative meningitis were more prominent in the cerebellum. Occasional small focal gliosis was also detected in brain stem. The disease process affected both white and grey matter.

Neuronal degeneration and necrosis (Fig. 1B and C) were more noticeable in the spinal cord and brain stem. Despite considerable tissue distortion some neuronal changes such as cytoplasmic hypereosinophilia, central chromatolysis, nuclear karyorrhexis, karyopyknosis or their absence, were suggestive of degeneration and necrosis (Fig. 1B and C). Patchy white matter vacuolation was noticed in spinal cord section. Non-specific changes including oedema and random perivascular haemorrhages were also observed.

Eosinophilic intra-cytoplasmic viral inclusions (Negri bodies) in Purkinje neurones (Fig. 1B) and scattered elsewhere (Fig. 1C) were supportive of virus infection. Oligo-inclusions were often relatively large spheroids which were intensely eosinophilic and had a tendency to occur peripherally close to the cell membrane (Fig. 1B). Poly-inclusions were numerous, small, and irregularly shaped with varying staining intensity and often had a centro-positioning affinity (Fig. 1C).
The immuno-histochemistry (IHC) slides showed widespread presence of viral nucleoprotein antigen in all of the examined sections (Fig. 1D-F). The particulate antigen staining of variable size was found within the cytoplasm of the nerve cell bodies and in the neuropil. Each of the five primary antibodies stained in a similar manner.

\subsection{FAT and real-time $P C R$}

The brain was reactive with antibodies to lyssavirus using the immunofluorescent antibody test (data not shown). RNA extracts from oral swabs (H1 and 2) and brain (H2) were also positive in the YBST strain-specific realtime RT-PCR (Smith et al., 2002) but were negative in the pteropid strain specific real-time RT-PCR. Retrospective testing by real-time PCR of a retained oral swab from the H1 was also consistent with YBST strain lyssavirus infection. This confirmed the diagnosis of lyssavirus infection by histopathology.

\subsection{Analysis of $A B L V$ horse isolate}

An isolate was obtained from the brain of the infected horse using mouse neuroblastoma cells (MNA). Sequencing was performed on the isolate (GenBank accession number: KJ685548) which included the entire predicted open reading frames (ORFs). A global nucleotide sequence alignment with the two currently available ABLV genome sequences (Fig. 2A) revealed that the isolate was most similar to a strain from the insectivorous microbat Saccolaimus flaviventris (Gould et al., 2002) with which it had a $97.7 \%$ sequence identity, compared to only $82.6 \%$ shared identity with the human isolate of flying fox origin.

\section{Discussion}

Under normal circumstances, in cases of horses with neurological symptoms, samples are submitted for Hendra virus ( $\mathrm{HeV}$ ) infection exclusion, and ABLV testing should be considered as a differential diagnosis; however, this is not always possible as veterinarians are reluctant to undertake autopsies of such horses. Alternative sampling methods should be considered, such as the occipital foramen method (Barrat and Blancou, 1988) or the retro-orbital method (Montano Hirose et al., 1991). If Hendra testing by real-time PCR returns negative results, samples are tested additionally for flaviviruses and also equine herpesvirus type 1 which are known to cause neurological disease in horses. With regard to the latter, there were no reports of infection in Queensland; however, there have been two cases elsewhere in Australia (Carroll and Westbury, 1985; Studdert et al., 2003).

The fact that oral swabs from both horses were positive is significant because the use of oral swabs from horses with neurological signs may improve the confidence in the diagnosis. It is a well-established fact that rabies virus is transmitted through saliva of a rabid animal (Vaughn et al., 1965). Echevarría et al. (2001) have successfully used oropharyngeal swabs for epidemiological studies of EBLV in a serotine bat colony. However, it would be risky to base the diagnosis on oropharyngeal swab/saliva testing alone 

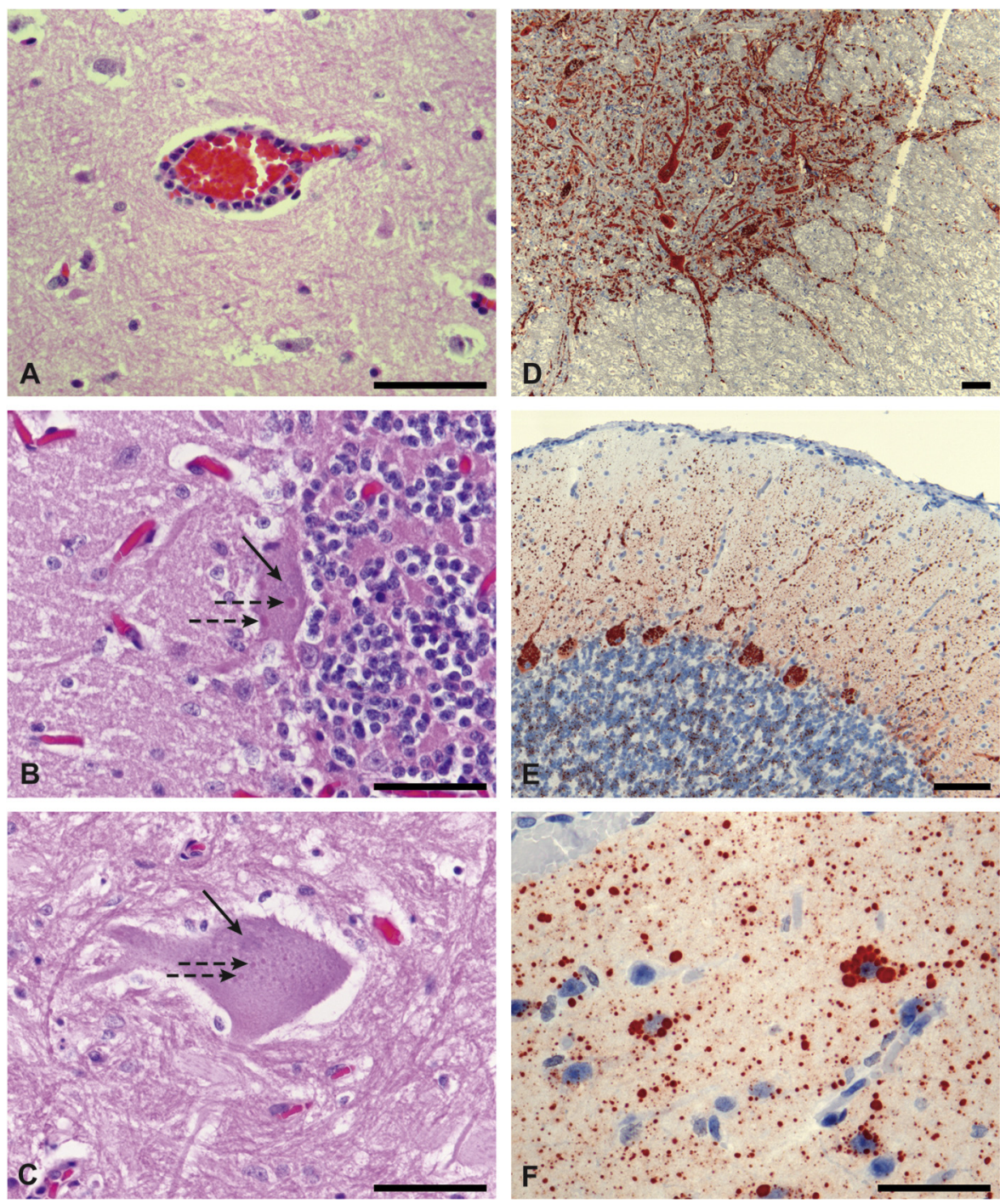

Fig. 1. Histopathological and immunohistochemical findings for Horse 2. (A) Cerebrum: small vessel with thin perivascular cuff (predominantly lymphocytic), indicative of non-suppurative encephalitis (haematoxylin and eosin, H\&E). (B) Cerebellum: neuronal intra-cytoplasmic eosinophilic viral inclusions (broken arrows) within large Purkinje cell body. Note the indicators of cell degeneration: poorly discernable nucleus of Purkinje cell (solid black arrow). (C) Cervical spinal cord, showing large neuron with disintegrating nucleus and multiple small eosinophilic intracytoplasmic inclusions (broken arrows). Note the faint-staining degenerate nucleus (solid arrow) (H\&E). (D) Cervical spinal cord demonstrating dense and widespread viral antigen in grey matter (immunohistochemistry (IHC) for Lyssavirus nucleoprotein - brownish red colour). (E) Cerebellum, showing viral antigen distributed throughout the layers of the grey matter and which is particularly dense in the Purkinje cell bodies (IHC). (F) Cerebral cortex, showing variable-sized particulate viral antigen bodies in the cytoplasm of neurons and in the neuropil. Scale bars: $50 \mu \mathrm{m}$ for A, B, C and F; $100 \mu \mathrm{m}$ for D and E. (For interpretation of the references to color in text, the reader is referred to the web version of this article.)

as the shedding of the virus through saliva is intermittent (Hemachudha et al., 2002; Leung et al., 2007). Therefore, negative PCR results from saliva samples should be interpreted with caution.

In this case a multidisciplinary diagnostic approach enabled a correct diagnosis of ABLV infection. The preliminary histopathological findings were essential for the diagnostic outcome. Most of the detected histological features in this case are similar to those described in ABLV infected bat brains (Hooper et al., 1999) and recorded human ABLV infection (Samaratunga et al., 1998). The diagnosis of ABLV infection in this case clearly highlights the importance of basic first principles in significant veterinary diagnoses. The initial observation of Negri bodies in the cerebellum suggested a lyssavirus infection. This was confirmed using the FAT, which is the accepted universal assay for all lyssaviruses. Further investigation including virus isolation, sequencing of the entire ORF of the isolate and real-time RT-PCR enabled the identification of the pathogen as the YBST bat strain of ABLV. Other workers have reported difficulties detecting bat lyssavirus in the brain of other species including cats (Dacheux et al., 2009), sheep (Tjørnehøj et al., 2006) and stone marten (Müller et al., 2004). Dacheux et al. (2009) hypothesised 


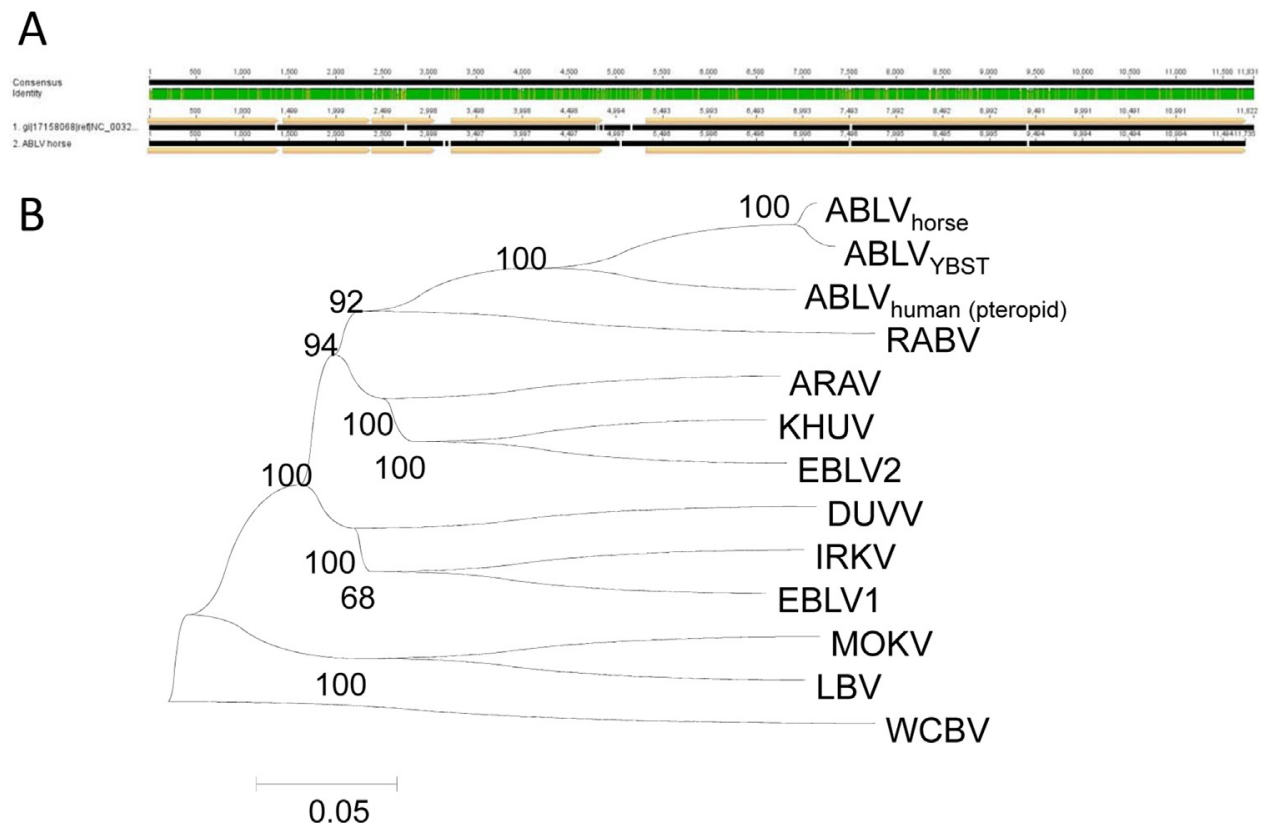

Fig. 2. Analysis of the genome of the $A B L V_{\text {horse }}$ isolate. $(A)$ The genome of the $A B L V_{\text {horse }}$ isolate was aligned with the $A B L V_{Y B S T}$ strain. The predicted open reading frames (ORFs) are shown in yellow and gaps are indicated by spaces. (B) A phylogenetic tree with the ABLV $V_{\text {horse }}$ isolate in relation to the other lyssavirus species including: ABLV (EF614261.1), European bat lyssavirus 2 (EU293114.1), Duvenhage virus (EU293119.1), Irkut virus (EF614260.1), European bat lyssavirus 1 (EU293112.1), Mokola virus (NC_006429.1), Lagos bat virus (EU293108.1), and West Caucasian bat virus (EF614258.1) is shown. A complete genome sequence for the pteropid strain of ABLV was not available. The tree was constructed from an alignment of the nucleotide sequences covering the complete coding regions. Bootstrap values are shown as a percentage of 1000 replicates. (For interpretation of the references to color in text, the reader is referred to the web version of this article.)

that it was due to low amount of virus in the brain and suggested the use of variety of techniques to diagnose EBLV infection. Müller et al. (2004) reported a lack of sensitivity of FAT in the stone marten case, whereas the test was repeatedly negative and a definite diagnosis was only achieved by mouse inoculation and RT-PCR positive results. This is significant as FAT is considered the gold standard for lyssavirus detection in brain tissues. Contrary to what was previously reported for classical rabies in domestic species, Bingham and van der Merwe (2002) showed that the hippocampus and the cerebellum can yield negative FAT results in $4-5 \%$ of the cases, while different parts of the cerebrum can yield up to $11 \%$ of FAT negatives on known positive brains. They recommended the testing of multiple sub-samples of the brain, and in particular the thalamus, where viral antigen was most abundant.

The histo-pathological findings were consistent with a non-suppurative meningo-encephalitis of viral aetiology, which is characteristic of a lyssavirus infection. The presence of intracytoplasmic inclusions was indicative of typical Negri bodies, a pathogenomic feature of lyssavirus infection. It is interesting to note that according to other published works (Dacheux et al., 2009; Müller et al., 2004; Tjørnehøj et al., 2006) this seems to be a rare event as in most cases when domestic animals and foxes are infected with bat lyssaviruses, Negri bodies are rarely observed. The authors hypothesised that it might be due to a low viral load. It is to be noted in this particular case, the real-time
PCR (Ct of 24) and strong FAT staining suggested a high viral load.

Sequencing of the entire ORF of the isolate enabled its identification. Pairwise alignment of the genome sequence confirmed the isolates close association with the YBST bat strain (97.7\% identity). The genome sequence of an isolate that was obtained from a fatal human case in 1998 (Warrilow et al., 2002), who was infected by an unidentified species of flying fox, had only $82.6 \%$ nucleotide identity with the horse isolate. A phylogenetic analysis of the genome sequence confirmed the isolates close association with the YBST bat strain (Fig. 2B). Hence, the sequence analysis indicated that the horse was most likely infected by an YBST microbat.

The isolate had a putative transcription termination signal $\left(\mathrm{TGGA}_{6} \mathrm{C}\right)$ located between the phosphoprotein and matrix ORFs (Table 1 ) which differed from the consensus signal sequence $\left(\mathrm{TGA}_{7} \mathrm{C}\right)$ for lyssaviruses (Bourhy et al., 1990). Interestingly, a change in that signal sequence also occurred in an isolate from an insectivorous bat (Gould et al., 2002). In addition, a change was also reported previously in that signal for the isolate from the human ABLV infection (Warrilow et al., 2002). In that case, as the sequence change was only detectable in the isolate and not the original brain material, it was attributed to a possible cell culture adaptation. Hence for the horse isolate, this transcription termination signal change may also indicate an adaptation of the virus to cell culture. In addition, the horse isolate was different from the 
Table 1

Changes in the P-M transcription termination signal sequence.

\begin{tabular}{ll}
\hline Virus & P-M termination signal \\
\hline ABLV $_{\text {horse }}$ & TGGAAAAAAC \\
ABLV $_{\text {insectivorous }}$ & TGAGGAAGAC \\
ABLV $_{\text {human }}$ & TGAGAAAAAC \\
Consensus & TGAAAAAAAC \\
\hline
\end{tabular}

Differences from the consensus sequence are shown in bold.

insectivorous strain in a 7 amino acid region proximal to the two carboxy-terminal amino acids of the glycoprotein (Fig. 3). A similar observation was made previously when comparing the same region of the human isolate with the flying fox strain (Warrilow et al., 2002). As the changes varied depending on the host from which it was isolated, the sequence variability may reflect species-specific adaptation.

Although Australia is considered free of rabies (AHA, 2011), there have been three human cases of ABLV infection of which two were due to the pteropid strain of ABLV and one was due to the insectivorous strain. Due to the low frequency of infections of the ABLV in general, and the YBST bat strain in particular, it was surprising that two infections of horses should have occurred simultaneously on the same property. Unlike the larger fruit bats that often interact with dogs and cats because they are more ubiquitous and often found feeding in backyards, insectivorous bats are more furtive and feed mainly by hawking (McKenzie, 2008). As a result, they are less likely to interact with companion and domestic animals. It is not known how the two horses were simultaneously infected. One possibility is that the horses may have come in contact with one or more lyssavirus-infected YBST bats and were either bitten or scratched by the latter, perhaps in the same incident. Subsequent investigations on the property failed to establish a direct link with YBST bats. It is also worth noting that this event could have happened anytime between 2 weeks and 2 years post-infection. In a series of studies (Constantine, 1966; Constantine et al., 1968; McColl et al., 2007; Murphy et al., 1980), it was shown that the majority of domestic animals experimentally infected, initially recovered and developed antibodies, but then some succumbed to rabies after 2 years. McColl et al. (2007) were unable to reproduce rabies in cats and dogs experimentally during a 3-month observation. All animals under investigation recovered and seroconverted within 2 weeks post infection. They concluded that there may be some difference in pathogenicity between terrestrialanimal-derived lyssaviruses and bat-derived lyssaviruses. However, the present report confirms that bat-derived

\section{ABLV $_{\text {insectivorous }}$ DRKVSVTSQSGKSIPSWESYK-SRQGHSRS ABLV $_{\text {human }}$ DRKVSVTSQSGKVIPSWESYKIEAGGHERS ABLV $_{\text {horse }} \quad$ DRKVSVTSQSGKSIPSWESYKIETGGNSRS}

Fig. 3. The variable carboxy-terminus of the $G$ protein. An alignment of the 30 amino acids residues at the carboxy-terminus of the ABLV horse isolate with the human and insectivorous sequences reveals variability in a 7 amino acid region (boxed). lyssaviruses infections can be as fatal as terrestrial animalderived lyssavirus infection.

Currently, Australian legislation does not allow the vaccination of domestic animals against rabies unless they are imported or exported. This policy may need to be re-considered as it is now clear that ABLV infection presents a risk to domestic animals, their human owners and veterinary workers.

\section{Conflict of interest}

The authors have no conflict of interest to declare

\section{Acknowledgements}

The authors would like to acknowledge Dr. Anita Gordon (Biosecurity Sciences Laboratory, DAFF) for her preliminary assessment of the histological changes, which led to the diagnosis of ABLV infection in the second horse.

\section{References}

AHA, 2011. Disease strategy: rabies (version 3.0) In: Australian Veterinary Emergency Plan (AUSVETPLAN). Primary Industries Council, Canberra, ACT

Allworth, A., Murray, K., Morgan, J., 1996. A human case of encephalitis due to a lyssavirus recently identified in fruit bats. Commun. Dis. Intell. 20,, 504-504.

Banyard, A.C., Johnson, N., Voller, K., Hicks, D., Nunez, A., Hartley, M., Fooks, A., 2009. Repeated detection of European bat lyssavirus type 2 in dead bats found at a single roost site in the UK. Arch. Virol. 154, 1847-1850.

Barrat, J., Blancou, J., 1988. Technique simplifiée de prélèvement, de conditionnement et d'expédition de matière cérébrale pour le diagnostic de rage. Doc. OMS/Rab. Res./88.27.

Bengis, R., Leighton, F., Fischer, J., Artois, M., Morner, T., Tate, C., 2004. The role of wildlife in emerging and re-emerging zoonoses. Rev. Sci. Tech. 23, 497-512

Bingham, J., van der Merwe, M., 2002. Distribution of rabies antigen in infected brain material: determining the reliability of different regions of the brain for the rabies fluorescent antibody test. J. Virol. Methods 101, 85-94.

Black, E.M., Lowings, J.P., Smith, J., Heaton, P.R., McElhinney, L.M., 2002. A rapid RT-PCR method to differentiate six established genotypes of rabies and rabies-related viruses using TaqMan ${ }^{\mathrm{TM}}$ technology. J. Virol. Methods 105, 25-35.

Bourhy, H., Sureau, P., Tordo, N., 1990. From rabies to rabies-related viruses. Vet. Microbiol. 23, 115-128.

Brookes, S.M., Klopfleisch, R., Müller, T., Healy, D.M., Teifke, J.P., Lange, E., Kliemt, J., Johnson, N., Johnson, L., Kaden, V., 2007. Susceptibility of sheep to European bat lyssavirus type-1 and-2 infection: a clinical pathogenesis study. Vet. Microbiol. 125, 210-223.

Carroll, C., Westbury, H., 1985. Isolation of equine herpesvirus 1 from the brain of a horse affected with paresis. Aust. Vet. J. 62, 345-346.

Cliquet, F., Picard-Meyer, E., Barrat, J., Brookes, S., Healy, D., Wasniewski, M., Litaize, E., Biarnais, M., Johnson, L., Fooks, A., 2009. Experimental infection of Foxes with European bat lyssaviruses type-1 and 2. BMC Vet. Res. 5, 19.

Constantine, D., 1966. Transmission experiments with bat rabies isolates: reaction of certain Carnivora, opossum, and bats to intramuscular inoculations of rabies virus isolated from free-tailed bats. Am. J. Vet. Res. 27, 16.

Constantine, D., Solomon, G., Woodall, D., 1968. Transmission experiments with bat rabies isolates: responses of certain carnivores and rodents to rabies viruses from four species of bats. Am. J. Vet. Res. 29, $181-190$.

Dacheux, L., Larrous, F., Mailles, A., Boisseleau, D., Delmas, O., Biron, C., Bouchier, C., Capek, I., Muller, M., Ilari, F., 2009. European bat lyssavirus transmission among cats, Europe. Emerg. Infect. Dis. 15, 280.

Echevarría, J.E., Avellón, A., Juste, J., Vera, M., Ibáñez, C., 2001. Screening of active lyssavirus infection in wild bat populations by viral RNA detection on oropharyngeal swabs. J. Clin. Microbiol. 39, 3678-3683. 
Favoretto, S., de Mattos, C., de Mattos, C., Campos, A., Sacramento, D., Durigon, E., 2013. The emergence of wildlife species as a source of human rabies infection in Brazil. Epidemiol. Infect. 141, 1552-1561.

Fooks, A., 2004. The challenge of new and emerging lyssaviruses. Expert Rev. Vaccines 3, 333-336.

Fooks, A.R., McElhinney, L.M., Pounder, D.J., Finnegan, C.J., Mansfield, K., Johnson, N., Brookes, S.M., Parsons, G., White, K., McIntyre, P.G., 2003. Case report: isolation of a European bat lyssavirus type 2a from a fatal human case of rabies encephalitis. J. Med. Virol. 71, 281-289.

Foord, A.J., Heine, H.G., Pritchard, L.I., Lunt, R.A., Newberry, K.M., Rootes, C.L., Boyle, D.B., 2006. Molecular diagnosis of lyssaviruses and sequence comparison of Australian bat lyssavirus samples. Aust. Vet. J. 84, 225-230.

Fraser, G.C., Hooper, P.T., Lunt, R.A., Gould, A.R., Gleeson, L.J., Hyatt, A.D., Russell, G.M., Kattenbelt, J.A., 1996. Encephalitis caused by a lyssavirus in fruit bats in Australia. Emerg. Infect. Dis. 2, 327.

Gould, A.R., Hyatt, A.D., Lunt, R., Kattenbelt, J.A., Hengstberger, S., Blacksell, S., 1998. Characterisation of a novel lyssavirus isolated from Pteropid bats in Australia. Virus Res. 54, 165-187.

Gould, A.R., Kattenbelt, J.A., Gumley, S.G., Lunt, R.A., 2002. Characterisation of an Australian bat lyssavirus variant isolated from an insectivorous bat. Virus Res. 89, 1-28.

Hanna, J.N., Carney, I.K., Smith, G.A., Tannenberg, A., Deverill, J.E., Botha, J.A., Serafin, I.L., Harrower, B.J., Fitzpatrick, P.F., Searle, J.W., 2000. Australian bat lyssavirus infection: a second human case, with a long incubation period. Med. J. Aust. 172, 597-599.

Hemachudha, T., Laothamatas, J., Rupprecht, C.E., 2002. Human rabies: a disease of complex neuropathogenetic mechanisms and diagnostic challenges. Lancet Neurol. 1, 101-109.

Hooper, P., Fraser, G., Foster, R., Storie, G., 1999. Histopathology and immunohistochemistry of bats infected by Australian bat lyssavirus. Aust. Vet. J. 77, 595-599.

Hooper, P., Lunt, R., Gould, A., Samaratunga, H., Hyatt, A., Gleeson, L., Rodwell, B., Rupprecht, C., Smith, J., Murray, P., 1997. A new lyssavirus - the first endemic rabies-related virus recognized in Australia. Bulletin de l'Institut Pasteur 95, 209-218.

Kearse, M., Moir, R., Wilson, A., Stones-Havas, S., Cheung, M., Sturrock, S., Buxton, S., Cooper, A., Markowitz, S., Duran, C., Thierer, T., Ashton, B., Meintjes, P., Drummond, A., 2012. Geneious Basic: an integrated and extendable desktop software platform for the organization and analysis of sequence data. Bioinformatics 28, 1647-1649.

Krebs, J.W., Rupprecht, C.E., Childs, J.E., 2000. Rabies surveillance in the United States during 1999. J. Am. Vet. Med. Assoc. 217, 17991811.

Leung, A.K.C., Davies, H.D., Ellis, K.L., 2007. Rabies: Epidemiology, pathogenesis and prophylaxis. Adv Ther 24, 1340-1347.

McColl, K.A., Chamberlain, T., Lunt, R.A., Newberry, K.M., Westbury, H.A., 2007. Susceptibility of domestic dogs and cats to Australian Bat Lyssavirus (ABLV). Vet. Microbiol. 123, 15-25.
McKenzie, N.P.M., 2008. Saccolaimus flaviventrisIn: IUCN 2014. IUCN Red List of Threatened Species. Version 2014.1.

Montano Hirose, J., Bourhy, H., Sureau, P., 1991. Retro-orbital route for brain specimen collection for rabies diagnosis. Vet. Rec. 129, 291-292.

Müller, T., Cox, J., Peter, W., Schäfer, R., Johnson, N., McElhinney, L., Geue, J., Tjørnehøj, K., Fooks, A., 2004. Spill-over of European Bat Lyssavirus type 1 into a stone marten (Martes foina) in Germany. J. Vet. Med. B 51, 49-54.

Murphy, F., Bell, J., Bauer, S., Gardner, J., Moore, G., Harrison, A., Coe, J., 1980. Experimental chronic rabies in the cat. Lab. Invest. 43, 231-241.

Ronsholt, L., 2002. A new case of European Bat Lyssavirus (EBL) infection in Danish sheep. Rabies Bull. Eur. 26, 15.

Samaratunga, H., Searle, J., Hudson, N., 1998. Non-rabies Lyssavirus human encephalitis from fruit bats: Australian bat Lyssavirus (pteropid Lyssavirus) infection. Neuropathol. Appl. Neurobiol. 24, 331335

Smith, I.L., Northill, J.A., Harrower, B.J., Smith, G.A., 2002. Detection of Australian bat lyssavirus using a fluorogenic probe. J. Clin. Virol. 25, 285-291.

Studdert, M., Hartley, C., Dynon, K., Sandy, J., Slocombe, R., Charles, J., Milne, M., Clarke, A., El-Hage, C., 2003. Outbreak of equine herpesvirus type 1 myeloencephalitis: new insights from virus identification by PCR and the application of an EHV-1-specific antibody detection ELISA. Vet. Rec. 153, 417-423.

Tamura, K., Peterson, D., Peterson, N., Stecher, G., Nei, M., Kumar, S., 2011. MEGA5: molecular evolutionary genetics analysis using maximum likelihood, evolutionary distance, and maximum parsimony methods. Mol. Biol. Evol. 28, 2731-2739

Tjørnehøj, K., Fooks, A., Agerholm, J., Rønsholt, L., 2006. Natural and experimental infection of sheep with European bat lyssavirus type1 of Danish bat origin. J. Comp. Pathol. 134, 190-201.

Vázquez-Morón, S., Avellon, A., Echevarria, J., 2006. RT-PCR for detection of all seven genotypes of Lyssavirus genus. J. Virol. Methods 135, 281287.

Vaughn, J.B., Gerhardt, P., Newell, K.W., 1965. Excretion of street rabies virus in the saliva of dogs. J. Am. Med. Assoc. 193, 363-368.

Vos, A., Müller, T., Cox, J., Neubert, L., Fooks, A., 2004a. Susceptibility of ferrets (Mustela putorius furo) to experimentally induced rabies with European Bat Lyssaviruses (EBLV). J. Vet. Med. B 51, 55-60.

Vos, A., Müller, T., Neubert, L., Zurbriggen, A., Botteron, C., Pöhle, D. Schoon, H., Haas, L., Jackson, A., 2004b. Rabies in red foxes (Vulpes vulpes) experimentally infected with European bat lyssavirus type 1. J. Vet. Med. B 51, 327-332.

Wakeley, P., Johnson, N., McElhinney, L., Marston, D., Sawyer, J., Fooks, A., 2005. Development of a real-time, TaqMan reverse transcription-PCR assay for detection and differentiation of lyssavirus genotypes 1, 5, and 6. J. Clin. Microbiol. 43, 2786-2792.

Warrilow, D., Smith, I.L., Harrower, B., Smith, G.A., 2002. Sequence analysis of an isolate from a fatal human infection of Australian bat lyssavirus. Virology 297, 109-119. 